\title{
Performance Evaluation of Logistics Industry in Hubei Province Based on DEA
}

\author{
Fu Ganlan \\ School of Management \\ Wuhan University of Technology \\ Wuhan, China, 430070 \\ fuganlanwhut@163.com
}

\author{
Yun Jun \\ School of Management \\ Wuhan University of Technology \\ Wuhan, China, 430070 \\ yunjunwh@163.com
}

\begin{abstract}
As an important measure of development capability of the logistics industry, the study on logistics industry performance evaluation has been in the process of continuous development and perfection. In this paper, we construct the performance evaluation index system of the logistics industry and introduce Pearson correlation coefficient and DEA model, taking the logistics industry of Hubei Province as an example to evaluate the total technical efficiency, pure technical efficiency and scale efficiency. The results show that the pure technical efficiency of logistics industry in Hubei is superior to the total technical efficiency, and the development of logistics industry from 2005 to 2014 has a rising trend. The conclusion of this research has a great significance for the construction of logistics infrastructure, the improvement of resource utilization rate, the improvement of the quality of logistics personnel, the rational allocation of human resources and the construction of logistics information platform.
\end{abstract}

Keywords-DEA; Logistics Industry; Performance Evaluation; Pearson correlation analysis

\section{INTRODUCTION}

Logistics industry, an emerging service sector of national economy, the state has paid more and more attention to them in recent years, a series of relevant policies and documents have been introduced to promote its rapid development. Hubei Province, followed by the pace of the country, under the background of the east and west of the geographical advantages, the continuous development of transportation and the increment of product demand, increases the logistics infrastructure construction, pays attention to urban logistics planning, and promotes the development of the logistics industry. Therefore, optimizing the logistics industry resource allocation and improving the performance of the logistics industry become an urgent problem to be solved in the healthy and stable development of the logistics industry. It also become the focus of attention and the effective basis of the government in the decision-making process. This article is exactly expounded on this study.

There are some achievements in the study of the evaluation of logistics industry performance both at home and abroad. In foreign countries, Schinna used the input-oriented model analysis in data envelopment analysis method to evaluate the third-party logistics enterprises efficiency and to select the third party logistics enterprises [1]. Rogers used the input-oriented model in data envelopment analysis to analyze the operational efficiency of 19 warehouses in the United States [2]. Rabinovic used DEA model to evaluate the efficiency of logistics enterprises in the United States, and the impact of logistics service performance and service breadth on production efficiency were analyzed [3]. Weber only built the input index DEA model based on the Schinnar model [4]. Banker used the DEA method to establish the model, evaluating the enterprise's technical inefficiency and scale inefficiency [5]. In the domestic, Liu Wei used the Bootstrap-Malmquist method in DEA to measure the technological innovation efficiency of China's high-tech industry from 2001 to 2009 [6]. He Yong used DEA and ANN to study the average level of industrial energy efficiency in 30 regions of China from 2005 to 2012 [7]. Huang Hao used DEA model to analyze 7 ordinary high school education cost efficiency of Lianyungang in Jiangsu, to a certain extent, reflecting the input and output of educational resources [8]. Wang Qun used DEA model to conduct horizontal study of the city's logistics industry input-output efficiency based on the eight prefecture-level cities in Yunnan Province [9].

Most of the studies in the selection of factors directly refers to the relevant literature indicators, not to test the rationality of the selection of indicators. Fortunately the DEA model can distinguish the effective decision-making unit, and it is also good to improve redundant inputs and get good returns. So in this study, we will carry out research and exploration through constructing the DEA model.

\section{Model Establishment}

In 1978, A. Charnes and W.W. Cooper put forward the data envelope analysis method, referred to as DEA, based on the "relative validity evaluation". DEA is used to evaluate the relative effectiveness of departments or units. There are a number of corresponding input and output factors, which forming a specific economic system in the process of putting into certain elements to achieve good results.

In view of the present situation and characteristics of logistics industry in Hubei Province, this paper tries to analyze the influencing factors of logistics industry performance and test the rationality of inspection index selection. On the basis of the characteristics of DEA model, the CCR model and BCC model in DEA model are used to analyze the development of logistics industry in Hubei Province.

Suppose there are $\mathrm{n}$ decision-making units, each 
decision-making unit, denoted as $\mathrm{DMU}_{\mathrm{j}}$, has $\mathrm{m}$ types of input indicators and $\mathrm{s}$ types of output indicators, and they are respectively denoted as $x_{j}$ and $y_{j}$ of the $j$ decision-making unit input and output, which $\theta$ is the total technical efficiency of the logistics industry, $\lambda_{j}$ is the input-output coefficient, $s^{-}$and $s^{+}$prospectively represent the slack variable for the input and output slack variable. The CCR model is shown in formula (1)When the convex constraint condition, $\sum_{j=1}^{n} \lambda^{*}$,is added to the CCR model, the BCC model is obtained in formula (2), which $\sigma$ is the pure technical efficiency value of the logistics industry, $\lambda_{\mathrm{j}}, \mathrm{s}^{-}, \mathrm{s}^{+}$ and $\sigma$ are the amount of parameter to be estimated.

$$
\begin{gathered}
\min \theta-\varepsilon\left(\sum_{r=1}^{s} s_{r}^{+}+\sum_{q=1}^{m} s_{q}^{-}\right) \\
\left\{\begin{array}{c}
\sum_{j=1}^{m} x_{j} \lambda_{j}+s^{-}=\theta x_{j} \\
\sum_{j=1}^{s} y_{j} \lambda_{j}-s^{+}=y_{j} \\
\lambda_{j} \geq 0,(j=1,2, \ldots, n) \\
s^{-} \geq 0, s^{+} \geq 0 \\
\min \delta-\varepsilon\left(\sum_{r=1}^{s} s_{r}^{+}+\sum_{q=1}^{m} s_{q}^{-}\right) \\
\sum_{j=1}^{m} x_{j} \lambda_{j}+s^{-}=\delta x_{j} \\
\sum_{j=1}^{s} y_{j} \lambda_{j}-s^{+}=y_{j} \\
\sum_{j=1}^{n} \lambda^{*}=1 \\
\lambda_{j} \geq 0,(j=1,2, \ldots, n) \\
s^{-} \geq 0, s^{+} \geq 0
\end{array}\right.
\end{gathered}
$$

\section{EMPIRICAL RESEARCH}

\section{A. Indicator selection basis}

At present, the logistics input and output indicators have not yet formed a unified evaluation system, different regional logistics industry has different development trend, and its input and output indicators are also different. Based on the DEA evaluation system, for the logistics industry development performance, the logistics industry mainly puts into a reasonable resource elements and produces some economic benefits. In terms of investment, the input indicators are mainly explored from the three aspects of the human, material and financial resources of the logistics industry. The human resources of the logistics industry are related to the logistics industry practitioners and the number of logistics enterprises, the material resources mainly concern the length of the transport routes related to the logistics infrastructure and resource consumption, grade highway mileage and energy consumption of logistics industry, the financial performance mostly concludes the total investment in fixed assets related to investment of the logistics industry and so on. The investment of these elements will produce the logistics industry, the total social, passenger volume, cargo volume, cargo turnover, logistics and other economic benefits.

Therefore, taking into account of the representativeness of indicators and the availability of data, combined with the scientific selection of input and output indicators of logistics industry efficiency in different regions at different times, this paper chooses logistics industry practitioners $x_{1}$, the total investment of logistics industry $x_{2}$ and grade highway mileage $x_{3}$ as input indicators from the macroscopic point of view , and selects the cargo turnover $y_{1}$, freight volume $y_{2}$ and logistics industry added value $y_{3}$ for the output indicators as output indicators to evaluate the development of logistics industry in Hubei Province performance.

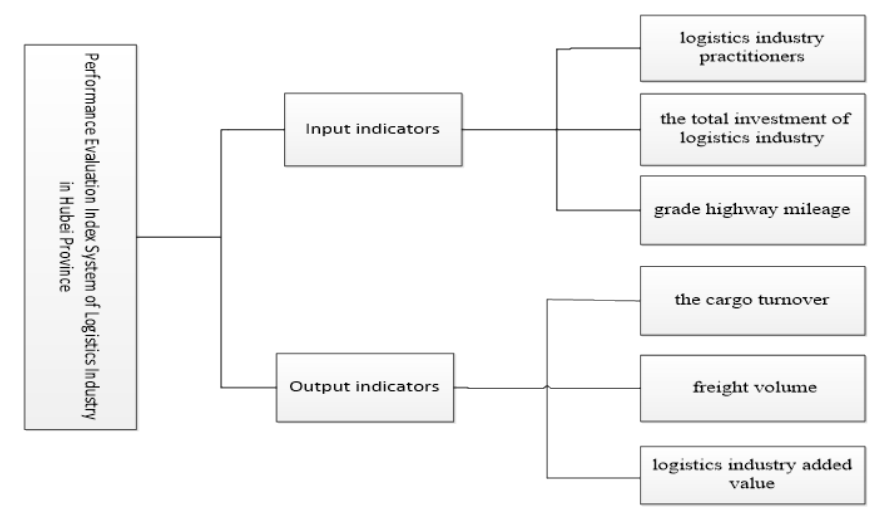

Fig. 1. The performance evaluation index system of the logistics industry in Hubei Province

\section{B. Indicators selection and data processing}

The data of input and output indicators is from China Statistical Yearbook (Hubei) and the national economic and social development statistics in Hubei Province, which is shown in Table 1.

TABLE I. THE DATA OF INPUT AND OUTPUT INDICATORS

\begin{tabular}{ccccccc}
\hline Year & $x_{1}$ & $x_{2}$ & $x_{3}$ & $y_{1}$ & $y_{2}$ & $y_{3}$ \\
\hline 2005 & 24.7 & 292.73 & 7.61 & 1415.70 & 46766 & 370.36 \\
2006 & 26.5 & 442.46 & 13.58 & 1489.00 & 49305 & 431.32 \\
2007 & 27.2 & 496.58 & 14.72 & 1644.70 & 54909 & 485.87 \\
2008 & 28.9 & 538.6 & 15.37 & 2526.39 & 71900 & 562.46 \\
2009 & 29.5 & 767.42 & 16.88 & 2566.36 & 78984 & 642.72 \\
2010 & 28.6 & 935.3 & 18.78 & 3097.29 & 93422 & 753.61 \\
2011 & 29.2 & 1030.82 & 19.65 & 3798.84 & 106913 & 869.48 \\
2012 & 28.7 & 1266.58 & 20.31 & 4439.82 & 122945 & 934.96 \\
2013 & 30.2 & 1634.91 & 21.29 & 4751.83 & 131000 & 1078.11 \\
2014 & 31.7 & 1879.69 & 22.42 & 5503.57 & 150762 & 1181.58 \\
\hline
\end{tabular}

\section{Pearson correlation analysis}

After the establishment of indicators and data acquisition, whether the selection of these indicators is scientific and reasonable, further quantitative analysis is needed in the previous basis for qualitative analysis, so the Pearson correlation coefficient method is used to analyze logistics industry-related factors, combined with SPSS16.0 software. When the significance level is 0.01 , the specific analysis results are shown in Table 2. 
TABLE II. CORRELATION

\begin{tabular}{|c|c|c|c|c|c|c|c|}
\hline variables & Correlation & $x_{1}$ & $x_{2}$ & $x_{3}$ & $y_{1}$ & $y_{2}$ & $y_{3}$ \\
\hline \multirow{3}{*}{$x_{1}$} & Pearson correlation & 1 & 0.852 & 0.917 & 0.855 & 0.860 & 0.870 \\
\hline & Significance & & 0.002 & 0.000 & 0.002 & 0.001 & 0.001 \\
\hline & $\mathrm{n}$ & 10 & 10 & 10 & 10 & 10 & 10 \\
\hline \multirow{3}{*}{$x_{2}$} & Pearson correlation & 0.852 & 1 & 0.892 & 0.977 & 0.982 & 0.989 \\
\hline & Significance & 0.002 & & 0.001 & 0.000 & 0.000 & 0.000 \\
\hline & $\mathrm{n}$ & 10 & 10 & 10 & 10 & 10 & 10 \\
\hline \multirow{3}{*}{$x_{3}$} & Pearson correlation & 0.917 & 0.892 & 1 & 0.899 & 0.909 & 0.923 \\
\hline & Significance & 0.000 & 0.001 & & 0.000 & 0.000 & 0.000 \\
\hline & $\mathrm{n}$ & 10 & 10 & 10 & 10 & 10 & 10 \\
\hline \multirow{3}{*}{$y_{1}$} & Pearson correlation & 0.855 & 0.977 & 0.899 & 1 & 0.999 & 0.993 \\
\hline & Significance & 0.002 & 0.000 & 0.000 & & 0.000 & 0.000 \\
\hline & $\mathrm{n}$ & 10 & 10 & 10 & 10 & 10 & 10 \\
\hline \multirow{3}{*}{$y_{2}$} & Pearson correlation & 0.860 & 0.982 & 0.909 & 0.999 & 1 & 0.996 \\
\hline & Significance & 0.001 & 0.000 & 0.000 & 0.000 & & 0.000 \\
\hline & $\mathrm{n}$ & 10 & 10 & 10 & 10 & 10 & 10 \\
\hline \multirow{3}{*}{$y_{3}$} & Pearson correlation & 0.870 & 0.989 & 0.923 & 0.993 & 0.996 & 1 \\
\hline & Significance & 0.001 & 0.000 & 0.000 & 0.000 & 0.000 & \\
\hline & $\mathrm{n}$ & 10 & 10 & 10 & 10 & 10 & 10 \\
\hline
\end{tabular}

As is shown from Table 2, the correlation coefficient between the logistics industry practitioners, logistics industry, the total investment in fixed assets, grade highway mileage of the input indicators and cargo turnover, freight volume, logistics industry added value of the output indicators are respectively above 0.8 at the level of significance of 0.01 , which indicates that the change of the input index will have an impact on the output indicators Compared with the output indicators, the selection of the input indicators are reasonable and they are the important input factors, So they can be used for further analysis.

\section{DEA results analysis}

As is shown in Table 2, the data of indicators shows a reasonable trend, which suggests the scientific selection of indicators, thus representing an objective performance level of logistics industry in Hubei Province.

In this paper, the DEA2.1 software is used to analyze the technical efficiency analysis of the logistics industry in Hubei Province from 2005 to 2014.
TABLE III. TECHNICAL EFFICIENCY VALUE

\begin{tabular}{|c|c|c|c|c|c|c|}
\hline Year & $\theta$ & $\delta$ & $\begin{array}{l}\omega \\
=\frac{\theta}{\delta}\end{array}$ & $\begin{array}{l}\text { Returns to } \\
\text { scale }\end{array}$ & $\mathrm{s}_{\mathrm{i}}^{-}, \mathrm{s}_{\mathrm{i}}^{+}$ & $\begin{array}{c}\text { DEA } \\
\text { efficiency }\end{array}$ \\
\hline 2005 & 1.000 & 1.000 & 1.000 & - & All 0 & valid \\
\hline 2006 & 0.895 & 0.948 & 0.944 & irs & $\begin{array}{l}\text { Not all } \\
0\end{array}$ & invalid \\
\hline 2007 & 0.930 & 0.945 & 0.984 & irs & $\begin{array}{c}\text { Not all } \\
0\end{array}$ & invalid \\
\hline 2008 & 1.000 & 1.000 & 1.000 & - & All 0 & valid \\
\hline 2009 & 0.908 & 0.918 & 0.989 & irs & $\begin{array}{c}\text { Not all } \\
0\end{array}$ & invalid \\
\hline 2010 & 0.939 & 0.971 & 0.967 & irs & $\begin{array}{l}\text { Not all } \\
0\end{array}$ & invalid \\
\hline 2011 & 1.000 & 1.000 & 1.000 & - & All 0 & valid \\
\hline 2012 & 1.000 & 1.000 & 1.000 & - & All 0 & valid \\
\hline 2013 & 1.000 & 1.000 & 1.000 & - & All 0 & valid \\
\hline 2014 & 1.000 & 1.000 & 1.000 & - & All 0 & valid \\
\hline $\begin{array}{l}\text { average } \\
\text { value }\end{array}$ & 0.967 & 0.978 & 0.988 & & & \\
\hline
\end{tabular}

As is shown in table 3, the total technical efficiency of logistics industry in Hubei Province from 2005 to 2014 is 0.967 , the average pure technical efficiency is 0.978 and the scale efficiency is 0.988 , which suggests the overall logistics industry performance is higher, and the input and output factors of the logistics industry in Hubei Province are more reasonable from the time dimension, but there are some deficiencies, the details are as follows.

In the total technical efficiency, its value is 1 in 2005, 2008, 2011-2014, which is up to DEA effective, indicating that infrastructure, technology, personnel and other logistics elements on the basis of investment resources in Hubei Province have been fully utilized, the output level achieves the best. The remaining years of the total technical efficiency value is less than 1 , resource investment has a certain blindness and has not been rationally used, Resulting the imbalance between inputs and outputs, which should be a reasonable combination of inputs and outputs.

In terms of pure technical efficiency, the pure technical efficiency is better than the total technical efficiency. In terms of years, the pure technical efficiency values are 1 in 2005, 2008 and 2011, respectively, which is DEA effective. The pure technical efficiency values in 2006-2007, 2009-2010 is less than 1, just four years of total efficiency is less than 1 , indicating that the total technical efficiency of the four years does not reach DEA effective caused by the pure technical efficiency, to a certain extent, Which reflects the lack of full utilization of resources due to technology level and mismanagement. In order to improve pure technical efficiency of the logistics industry, the management level of logistics industry needs to be improved, logistics and high-quality personnel should be absorbed, and advanced logistics technology must be introduced.

In terms of scale efficiency, the scale efficiency of logistics industry in Hubei Province was 1 in 2005, 2008 and 2014, the scale efficiency values of the remaining years were less than 1 , and the scale returns were increasing. The reason for the inefficiency of the scale efficiency in 2006 and 2007 is that the development of the logistics industry in Hubei Province has just started. The investment factors are low and the scale is 
small. In 2009-2010, the increment of the input factors has led to the continuous expansion of the resources and the unreasonable utilization of the resources. The proportion of input and output is not coordinated, resulting in lower efficiency. In 2011-2014,"Internet +" technology continues to penetrate, to a certain extent, which improves the logistics industry in Hubei Province performance.

Therefore, when the logistics industry develops at a certain stage, the scale should not be blindly expanded, the related department should be reasonable to optimize the allocation of resources, to improve the utilization of resource and to achieve a certain logistics elements on the basis of a reasonable output.

\section{CONCLUSION}

This paper takes the logistics industry performance in Hubei Province as the research object, combined with the development of the status quo and characteristics in recent years, thus constructing the logistics industry performance evaluation index system in Hubei. Pearson correlation coefficient method is used to analyze the factors of influencing the development of logistics industry and verify the rationality of indicators system. On the basis of this, the DEA model is used to analyze the technical efficiency of the logistics industry in Hubei Province from 2005 to 2014. On the whole, the technical efficiency values are high, indicating that the logistics industry in Hubei Province has a good development momentum, but there are some shortcomings, in some years, there is a phenomenon that resource elements are put into redundancy. It can be concluded that the development of logistics industry in Hubei Province shows a trend of rising trend, which shows great development opportunities, but it exists the phenomenon of resource elements redundancy. The relevant management departments need to take appropriate measures to optimize the rational allocation of resources, to improve the logistics industry in Hubei Province performance and thus to promote the sustainable development of logistics industry in Hubei Province.

\section{ACKNOWLEDGEMENT}

This study was supported by Ministry of Transport key Scientific and Technological project of China (Grant NO. 2015364811070), which was called "transportation industry information performance evaluation system and evaluation application research. All support is gratefully acknowledged.

\section{REFERENCES}

[1] Schinnar A.P. Measuring productive efficiency of public service provision [J]. University of Pennsylvania, School of Public and Urban Policy, 1980, (9):143-148.

[2] Rogers K.J. Evaluating the efficiency of 3PL logistics operations [J]. International Journal of Production Economics, 2007, (5):1-10.

[3] Elliot R. Logistics service providers in Internet supply chains [J]. California Management Review, 2006, 48(4):84-108.

[4] Weber C.A. A data envelopment analysis approach to measuring vendor performance [J].Supply Chain Management, 1996, (1):28-39.

[5] Banker R.D., Chmaes A., Cooper W.W. Models for the estimation of technical and scale inefficiencies in data envelopment analysis[J]. Management Science, 1984, (30):1078-1092.

[6] Liu Wei. Analysis on the Efficiency of Technological Innovation in High-tech Industry Based on Bootstrap-Malmquist Index [J]. Economic dynamics, 2013, 03: 42-52.

[7] He Yong, Ma Aiwen. Analysis on Industrial Energy Efficiency and its Influencing Factors of China's Provincial Regions based on DEA and ANN [J]. Mathematics in Practice and Theory, 2016, 09: 87-96.

[8] Huang Hao. An Analysis of Cost Efficiency of Ordinary High School Education Based on DEA [J]. CO-Operative Economy \& Science, 2012, 02: 116-117.

[9] Wang Qun, Mu Yanan. An Empirical Study on Urban Logistics Efficiency Evaluation Based on DEA Model - Taking Yunnan Province as an Example [J].Manager, 2015, 10: 157-158. 